\title{
Delayed Graft Dislocation After Thoracic Aortic Endovascular Repair
}

\author{
Piffaretti G, ${ }^{1}$ Negri S, ${ }^{1}$ Ferraro $S,{ }^{1}$ Bossi M, ${ }^{1}$ Rivolta $N,{ }^{1}$ Fontana $F,{ }^{2}$ Castelli $\mathrm{P}^{1}$
}

${ }^{1}$ Vascular Surgery, Department of Surgery and

Morphological Sciences,

${ }^{2}$ Interventional Radiology, Department of Radiology

Circolo University Hospital, University of Insubria

School of Medicine, Varese, Italy

\section{Corresponding author}

Gabriele Piffaretti

Vascular Surgery - Department of Surgery and

Morphological Sciences

Circolo University Hospital - University of Insubria

School of Medicine

Italy

E-mail: gabriele.piffaretti@uninsubria.it

\section{Citation}

Gabriele P, Silvia N, Stefania F, Matteo B, Nicola R, Federico $\mathrm{F}$ et al. Delayed Graft Dislocation After Thoracic Aortic Endovascular Repair. Kathmandu Univ Med J 2014;46(2):97-100

\author{
ABSTRACT \\ Background \\ Endograft dislocation in thoracic aorta has not been widely studied.
}

\section{Objectives}

The purpose of this study is to analyze the incidence and predisposing factor in a single centre experience after 117 procedures.

\section{Method}

Between November 2000 and December 2011, all consecutive patients undergoing endovascular repair for descending thoracic or thoraco-abdominal aortic disease were identified. Follow-up imaging protocol included triple-phase CT-angiography at 1, 4, and 12 months, and annually thereafter. Migration was defined as proximal/ distal movements $>10 \mathrm{~mm}$ relative to anatomical landmarks or any movement leading to symptoms or reintervention.

\section{Result}

We identified 117 patients. Mean follow-up was 32 months (range, 1-144). Overall, five $(4.3 \%)$ patients with thoracic EG dislocation were identified. Dislocation was classified as collapse/infolding in 3 cases and migration in 2. Mean delay of the dislocation was 12.7 months. Only one patient developed symptoms and required an additional endograft. In the group of dislocated endografts, mean age $(53 \pm 20$ vs. $68 \pm 15, P=.032)$ and the diameter of the aortic lesion were lower $(4.1 \mathrm{~cm} \pm 1.6$ vs. $5.6 \mathrm{~cm} \pm 1.8, P=.069$ ), and the proximal landing zone at "zones 2 and 3 " were more frequently used ( 5 vs. $65, P=0.81$ ). All but one patient with collapse/infolding are still alive and doing well at a mean follow-up of 80 months.

\section{Conclusion}

Dislocation is an infrequent complication, but not so rare. Young age, small aortic diameter, and proximal sealing at the distal arch were the most important data associated with this complication.

\section{KEY WORDS}

Endograft dislocation, endograft migration

\section{INTRODUCTION}

Several recent studies have confirmed the excellent results in terms of outcomes of thoracic aortic endovascular repair (TEVAR); however, the advent of new techniques has given rise to new types of complications either in terms of clinical sequelae or morphological changes of the aorta and of the devices. ${ }^{1-3}$ Therefore, it remains clear that imaging surveillance is required to detect post-procedural complications, especially those specifically related to the device itself such as endoleaks, material fatigue, persistent sac growth, and last but not the least endograft (EG) migration. ${ }^{4,5}$

Endograft migration has been defined as the loss of positional stability resulting from the pulsatile forces of blood flow. ${ }^{6}$ Late migration of the EG has been reported to occur in a wide range of $0 \%$ to $30 \%$ of patients, and was more frequently associated with first-generation devices, even or not in association with neck dilatation and device kinking. ${ }^{4-7}$ Currently, different U.S. pivotal trials have tested 
three main devices and the results coming from the midterm follow-up seemed to have a low migration potential ranging from $0.7 \%$ to $3.9 \% .^{1-3}$

Despite the progressive increase of use, even outside the instruction for use and in more challenging morphologies, the study of this complication in the thoracic area has not been widely performed: yet debate persists with regard to incidence and etiology, and necessary treatment. We report our experience of delayed EG dislocation after 117 consecutive TEVAR cases.

\section{METHODS}

\section{Patients population}

Between November 2000 and December 2011, all consecutive patients undergoing TEVAR for descending thoracic or thoraco-abdominal aortic disease were identified. The study was designed as a retrospective data analysis of a prospective, single-centre experience. All clinical and procedural data were prospectively collected and recorded onto computerized database registry that remained consistent over the study period. Data entry was managed by physicians involved into patient care. Information about demographics, co-morbidities, medical and surgical history, operative details and postoperative events during the hospital stay were all registered. All patients gave their consent to participate. The authors had full access to and take full responsibility for the integrity of the data. Briefly, intervention was generally performed under general anaesthesia with oro-tracheal intubation in the operating theatre; all interventions were performed in the theatre, fully equipped to perform either conventional or endovascular procedures; a portable C-arm fluoroscopy system (BV $300^{\circledR}$-Philips-Eindhoven; NDL; Vision FD Vario $3 \mathrm{D}^{\circledR}$-Ziehm; Reggio Emilia-IT) with digital subtraction angiography and roadmap capabilities was used. Three different devices were used in our experience: Talent/ Valiant/Captivia ${ }^{\circledR}$ (Medtronic Vascular-Santa Rosa; CAUSA), Excluder/TAG/C-TAG ${ }^{\circledR}$ (W. L. Gore and AssociatesFlagstaff; AZ-USA), and TX-1/TX-2 ${ }^{\circledR}$ (Cook-Bloomington; IN-USA). Generally, endograft with bare stents were not used for traumatic aneurysms or dissections. Controlled hypotension was used during the deployment of the EG; proximal attachment site of the endograft was routinely ballooned except for selective cases.

\section{Follow-up and imaging characteristics}

After intervention, the follow-up imaging protocol included chest X-rays and triple-phase CT-A performed at 1, 4, and 12 months after EG implantation and annually thereafter. CT-A was performed using a 64-detector row (Aquilion ${ }^{\circledR}$ Toshiba, Zoetermeer, NDL). Arterial and venous phase acquisitions were then performed. The post-processing (MPRs, MIPs, 3D images and virtual angioscopy) imaging was recently optimized using a work station (Vitrea ${ }^{\circledR}$-Vital Images, Plymouth, MN). The patients were evaluated for the presence of an endoleak, type of sac reperfusion, aneurysm expansion, and endoleak intervention. The CT-A examinations were evaluated on workstations by a team of a vascular surgeon and an interventional radiologist, using multiplanar reformatting capabilities and MIP/ $\mathrm{MPR} / 3 \mathrm{D}$ reconstruction to identify and classify the type of complication.

\section{Definition}

No specific reporting standards for TEVAR have been produced so far. Briefly, EG migration has been defined for proximal or distal movements $>10 \mathrm{~mm}$ relative to anatomical landmarks or any movement event leading to symptoms or requiring reintervention. ${ }^{6}$ Collapse was described as the radiologic detection of a wedge-shaped gap between the undersurface or the infolding of the EG with/without lost of apposition of the EG to the aortic wall along the lesser curve. ${ }^{8}$

\section{Data analysis}

Clinical data were prospectively recorded and tabulated with Microsoft Excel ${ }^{\circledR}$ (Microsoft Corp, Redmond, WA, USA). Continuous variables were tested for normal distribution by the Kolmogorov-Smirnov test and compared between groups with unpaired Student's t test for normally distributed values; otherwise, the Mann-Whitney $U$ test was employed. In case of dichotomous variables, group differences were examined by chi-square or Fisher exact tests as appropriate. Results are expressed as mean \pm SD for continuous variables and frequencies for the categorical ones. A 2-sided $\mathrm{P}$ value <.05 was considered statistically significant. Statistical analysis was computed with SPSS release for Windows (SPSS Inc. ${ }^{\circledR}$, Chicago, IL, USA).

\section{RESULTS}

We identified 117 patients. Males were 93 (79.5\%); mean age was $68 \pm 15$ years (range, 18-87 years). Rupture was discovered in 19 (16.2\%) cases, and TEVAR was performed on an emergency basis in $33(28.2 \%)$ cases. Pathologies included degenerative (either atherosclerotic or dissecting) aneurysm ( $\mathrm{n}=71,60.7 \%$ ), dissection/penetrating aortic ulcer/intramural hematoma ( $\mathrm{n}=30,25.6 \%$ ), and trauma ( $n=16,13.7 \%$ ). The aortic arch was the location or was involved in 42 (35.9\%) cases. Primary technical success was 95.7\% (112/117). Overall in-hospital mortality was $14.5 \%$ (17 of 117). Mean follow-up was 32 months (range, 1-144).

\section{Endograft dislocations}

Overall, five (4.3\%) patients with thoracic EG dislocation were identified. They were all males with a mean age of $53 \pm 20$ years (range, 17-68 years). The indications for the index TEVAR were degenerative aneurysms $(n=3)$, traumatic aortic transection ( $n=1)$, and symptomatic free-floating mural thrombus $(n=1)$. Dislocation was classified as collapse/infolding in 3 cases and migration in 2. Mean delay of the dislocation was 12.7 months. Of 
the three patients discovered to have collapse/infolding two were treated for non-aneurysmal diseases. Only one patient (collapse) developed symptoms for uncontrolled hypertension and required a secondary procedure to implant an additional EG in order to re-expand the first EG. Two patients had an asymptomatic infolding. Migration led to two devastating endoleaks: a proximal type 1 endoleak on day $6^{\text {th }}$ postoperatively of the index procedure, finally leading to a fatal sac rupture. The second migration occurred later on the follow-up: the patient was admitted for an hemorrhagic shock due to the sac rupture caused by a type Illa endoleak, and an emergency TEVAR was performed successfully.

We did not note significantly difference in terms of comorbidities between patients with dislocated EG and those without this complication (Tab. 1); only, mean age (53 \pm 20 vs. $68 \pm 15, P=.032$ ) differed significantly. In the group of dislocated EGs, the diameter of the aortic lesion was lower $(4.1 \mathrm{~cm} \pm 1.6$ vs. $5.6 \mathrm{~cm} \pm 1.8, \mathrm{P}=.069)$, and the proximal landing zone at "zones 2 and 3 " were more frequently used ( 5 vs. $65, P=0.81$ ), but did not reach statistical significance. During the follow-up, one patient died (asymptomatic infolding) 28 months later for a septic shock due to pneumonia; all the patients with EG collapse/ infolding are still alive and doing well with a mean followup of 80 months.

\section{DISCUSSION}

The main finding of our analysis is the significant relationship between migration and the younger age. This data could find some support in the study of Jonker et al. ${ }^{9}$ who identified different reasons to explain the phenomenon of collapse/ infolding: excessive oversizing, small radius of aortic arch curvature, maldeployment of the EG or progression of the aortic disease should be taken into account. It should be remembered that these characteristics are typically found in younger patients, as experienced in our cases.

The pathogenesis of EG collapse may be multifactorial, and other factors may impact the risk of this complication in individual patients as well. ${ }^{10}$ Trauma patients are typically young and may have relatively small aortas, which often necessitate excessive EG oversizing. The aortic anatomy may be crucial as well in the development of this complication. ${ }^{9,10}$ The mismatch between the EG and aortic diameter and the small radius to the curve of the aortic arch, appeared to be the most common causes of EG collapse in young patients, or in those with non-aneurysmatic lesions of the aorta such as the blunt trauma. All of them may lead to incomplete deployment and infolding of the EG, increasing the risk of a complete collapse. Looking at our cases, we can observe that all of these factors occurred in at least four of the five cases we have detected: in particular, we observed an EG dislocation in non-aneurysmatic lesions (2 cases) or in those aortas with acute arch angle (3 cases).
Table 1. Co-morbidities chart and risk factors of dislocated and not dislocated endografts

$\begin{array}{cc}\begin{array}{c}\text { Migra- } \\ \text { tion } \\ (n=5)\end{array} & \text { EG integrity } \\ & \end{array}$

Risk factors \& co-morbidities, (\%)

\begin{tabular}{lccc} 
Age, $( \pm$ SD $)$ & $53 \pm 20$ & $68 \pm 15$ & .032 \\
Male & $5(100)$ & $88(78.6)$ & .581 \\
Hypertension & $3(60)$ & $89(79.5)$ & .289 \\
IHD & $2(40)$ & $26(23.2)$ & .592 \\
\hline Arryhthmia & $1(20)$ & $19(16.9)$ & 1.0 \\
Obesity $(\mathrm{BMI}>30)$ & $2(40)$ & $35(31.2)$ & .650 \\
\hline Urgent & $2(40)$ & $28(27.7)$ & .601 \\
\hline EuroSCORE, $( \pm$ SD) & $6.7 \pm 2.8$ & $9.5 \pm 3.2$ & .057
\end{tabular}

\begin{tabular}{|c|c|c|c|}
\hline \multicolumn{4}{|l|}{ Lesions carachteristics, (\%) } \\
\hline Arch involvement & $3(60)$ & $39(34.8)$ & .348 \\
\hline Non-aneurysmal disease & $2(40)$ & $18(16.0)$ & .201 \\
\hline Rupture & $1(20)$ & $18(16.0)$ & 1.0 \\
\hline Thoracic $\varnothing,( \pm S D)$ & $4.1 \pm 1.6$ & $5.6 \pm 1.8$ & .069 \\
\hline Disease extension, $( \pm S D)$ & $14.5 \pm 7.6$ & $14 \pm 16$ & .944 \\
\hline \multicolumn{4}{|l|}{ Operative details, (\%) } \\
\hline Duration, $( \pm S D)$ & $89 \pm 47$ & $139 \pm 99$ & .265 \\
\hline Blood loss, $( \pm S D)$ & $140 \pm 160$ & $444 \pm 788$ & .392 \\
\hline LSA coverage & $1(20)$ & $35(31.2)$ & 1.0 \\
\hline Covered aorta, $( \pm S D)$ & $15.6 \pm 7.2$ & $18.3 \pm 15.1$ & .692 \\
\hline$>2 \mathrm{EG}$ & $2(40)$ & $25(22.3)$ & .325 \\
\hline Prox landing zone (2-3) & $5(100)$ & $65(58.0)$ & .081 \\
\hline No free-flow EG & $4(80)$ & $88(78.6)$ & 1.0 \\
\hline \multicolumn{4}{|l|}{ Postoperative course, (\%) } \\
\hline LOS, ( $\pm \mathrm{SD})$ & $14 \pm 15$ & $12 \pm 19$ & .817 \\
\hline In-H mortality & $1(9.1)$ & $16(14.3)$ & .550 \\
\hline \multicolumn{4}{|l|}{ Follow-up outcomes, (\%) } \\
\hline Follow-up, $( \pm S D)$ & $48 \pm 46$ & $31 \pm 32$ & .256 \\
\hline Dead & $1(25)$ & 30 (30.9) & 1.0 \\
\hline
\end{tabular}

LSA = left subclavian artery, EG = endograft

LOS = length of stay, In-H = in hospital

Migration and collapse could be very dangerous and may require challenging repair or conversion to open repair. The recent review of Jonker et al. ${ }^{9}$ compiled 60 cases of collapse/infolding: most patients did not have symptoms, and the abnormality was detected during standard follow-up imaging, supporting the importance of continued surveillance after TEVAR. Patients who had symptoms at diagnosis likely had a more severe aortic sub-occlusion than asymptomatic patients; common signs were decreased femoral pulses or acute renal failure due to malperfusion. Considering the collapsed EGs, we agreed with the available data of the literature: coarctation-like symptoms were experienced in one case only, and it was successfully managed using an additional EG to re-expand the infolded device. The core-lab analyses of the pivotal 
$\mathrm{TAG}^{\circledR}$ trial reported that none of the migrations were clinically significant except for an early one associated with an arch aneurysm..$^{1,4}$ Similarly, in the $\mathrm{TX}-2^{\circledR}$ trial none of them were associated with endoleak or sac expansion or required an intervention..$^{2,4}$ Our experience is in contrast to these latter data: whether it was a collapse or a migration of the extremities, dislocation became symptomatic in $60 \%$ of the cases.

In our experience the overall incidence rate of dislocation was $4.3 \%$ in the thoracic aorta; this data is slightly higher to the $0.7 \%$ to $3.9 \%$ rate reported in the current U.S. pivotal trials, but we should take into account that we included two different mechanism of endograft dislocation. ${ }^{1-3}$ Migration has been considered to be primarily caused by inadequate overlap of the components; less frequently, poor oversizing or disease progression resulted in slow enlargement of the landing zones and subsequent loss of fixation. ${ }^{4}$ The core laboratory of the VALOR trial noted four EG migrations $<12$ months:3 only one patient required an additional intervention related to the migration. The incidence of EG migration in the Talent $^{\circledR}$ thoracic retrospective registry was $1.6 \%$ and modular disconnection of $1.4 \%$; type III endoleak rate related to the migration was $0.7 \% .{ }^{11}$ This was precisely the most threatening situation encountered in our experience: the downward movement of the device caused two sac ruptures due to an endoleak, with fatal consequence in one of them. No further thoracic aortic ruptures were observed in our patients considering those with an endoleak: we did not have further type III endoleaks, and all others proximal or distal type I endoleaks were associated to disease progression or poor aortic coverage but no evidence of migration or thoracic endoleak-related death was observed. This data supports the treacherous meaning of the migration-related endoleaks. ${ }^{12}$

\section{CONCLUSION}

Our study is limited by its retrospective nature; the number of patients was not extensive enough to perform more detailed analyses. However, our $4.3 \%$ incidence rate is similar to the data available in literature: dislocation is an infrequent complication, but not so rare.

Young age was the most important data associated with this complication, as tended to be either the diameter of the aortic lesion or the proximal sealing in the subclavian zone: all these factors refer to non-aneurysmatic diseases of the aorta. This must be remember us that TEVAR should be adjusted accordingly to the morphological characteristics of each individual type of aortic disease.

We believe these data support again the importance of a rigorous follow-up program: first and foremost it should be intended to search for these specific complications, and to help the identification of predictive factors in order to optimize the risk stratification of the index intervention.

\section{REFERENCES}

1. Makaroun MS, Dillavou ED, Wheatley GH, Cambria RP; Gore TAG Investigators. Five-year results of endovascular treatment with the Gore TAG device compared with open repair of thoracic aortic aneurysms. J Vasc Surg 2008;47:912-8

2. Matsumura JS, Cambria RP, Dake MD, Moore RD, Svensson LG, Snyder S. International controlled clinical trial of thoracic endovascular aneurysm repair with the Zenith TX2 endovascular graft: 1-year results. J Vasc Surg 2008;47:247-257

3. Fairman RM, Criado F, Farber M, Kwolek C, Mehta M, White R, et al; VALOR Investigators. Pivotal results of the Medtronic Vascular Talent Thoracic Stent Graft System: the VALOR trial. J Vasc Surg 2008;48: 546-554

4. Chaer RA, Makaroun MS. Late failure after endovascular repair of descending thoracic aneurysms. Semin Vasc Surg 2009;22:81-6. Review

5. Piffaretti G, Mariscalco G, Lomazzi C, Rivolta N, Riva F, Tozzi M, et al. Predictive factors for endoleaks after thoracic aortic aneurysm endograft repair. J Thorac Cardiovasc Surg 2009;138:880-5

6. Prasad A, To LK, Gorrepati ML, Zarins CK, Figueroa CA. Computational analysis of stresses acting on intermodular junctions in thoracic aortic endografts. J Endovasc Ther 2011;18:559-568

7. Resch T, Koul B, Dias NV, Lindblad B, Ivancev K. Changes in aneurysm morphology and stent-graft configuration after endovascular repair of aneurysms of the descending thoracic aorta. J Thorac Cardiovasc Surg 2001;122:47-52

8. Ueda T, Fleischmann D, Dake MD, Rubin GD, Sze DY. Incomplete endograft apposition to the aortic arch: bird-beak configuration increases risk of endoleak formation after thoracic endovascular aortic repair. Radiology 2010;255:645-652

9. Jonker FH, Schlosser FJ, Geirsson A, Sumpio BE, Moll FL, Muhs BE. Endograft collapse after thoracic endovascular aortic repair. J Endovasc Ther 2010;17:725-734. Review

10. Tadros RO, Lipsitz EC, Chaer RA, Faries PL, Marin ML, Cho JS. A multicenter experience of the management of collapsed thoracic endografts. J Vasc Surg 2011;53:1217-1222

11. Ehrlich MP, Nienaber CA, Rousseau H, Beregi JP, Piquet P, Schepens M, et al. Short-term conversion to open surgery after endovascular stentgrafting of the thoracic aorta: the Talent thoracic registry. $J$ Thorac Cardiovasc Surg 2008;135:1322-6

12. Morales JP, Greenberg RK, Lu Q, Cury M, Hernandez AV, Mohabbat $W$, et al. Endoleaks following endovascular repair of thoracic aortic aneurysm: etiology and outcomes. J Endovasc Ther 2008;15:631-8 